\title{
Managing the consequences of aggressive conservative treatment for refractory retinoblastoma with vitreous seeding
}

\author{
Lidando com as consequências do tratamento agressivo para retinoblastoma refratário \\ com semeadura vítrea
}

Aubrey Brink ${ }^{1}$, Zélia Maria Correa ${ }^{1,2}$, James Geller ${ }^{1,2}$, Todd Abruzzo ${ }^{1,2}$, James J. Augsburger ${ }^{1,2}$

\begin{abstract}
A 4 year-old girl with bilateral, non-familial retinoblastoma (RB) was referred to our care after primary enucleation OS and active tumor OD refractory to multiple therapies (intravenous chemotherapy, laser/cryotherapy, and I-125 plaque radiotherapy). Vitreous seeding $\mathrm{OD}$, initially controlled by several sessions of Ophthalmic Artery Infusion Chemotherapy (OAIC) and periocular chemotherapy, recurred shortly thereafter. The patient underwent intravitreal (IVit) Melphalan injections achieving tumor control despite the concurrent development of keratopathy, pupillary synechiae, cataract, and necrosis of the inferior fornix and the adjacent orbital fat, all secondary to the treatments administered. Repeated amniotic membrane implants and tarsorrhaphy were performed to alleviate the symptoms. Despite being tumor free for 6 months, a poor fundus view and treatment-related complications prompted us to consider enucleation, but parents declined. Following recent negative magnetic resonance imaging (MRI), her cataract was removed. She was then found to have tumor recurrence. Her eye was enucleated 12 months ago and she recovered well from the surgery. As ocular oncology embarks in eye-preserving treatments for retinoblastoma, it is important to address the cumulative effects and associated impact of such treatments and the possibility of failure.
\end{abstract}

Keywords: Retinoblastoma/drug therapy; Retinoblastoma/surgery; Melphalan/ administration \& dosage; Vitreous body/pathology; Intravitreal injections; Retinal neoplasms/surgery; Eye enucleation; Humans; Female; Child; Case reports

\section{RESUMO}

Umamenina de 4 anos com retinoblastoma (RB) bilateral, não-familiarfoiencaminhada após enucleação OE e tumor ativo OD refratário a múltiplas terapias (quimioterapia endovenosa, laser/crioterapia e braquiterapia com 1-125). Semeadura vitrea OD, inicialmente controlada por inúmeras sessões de Quimioterapia Intra-Arterial Oftálmica (QIAO) e quimioterapia periocular, recorreu em seguida. Paciente recebeu injeções intravitreas de Melphalan obtendo controle tumoral apesar do desenvolvimento concomitante de ceratopatia, sinéquias pupilares, catarata, necrose do fórnice inferior e gordura periorbitária adjacente, todos secundários aos tratamentos usados. Implantes repetidos de membrana amniótica e tarsorrafias foram realizadas para mel hora sintomatológica. Apesar de estar livre de tumor por 6 meses, a baixa visibilidade do fundo e complicações terapêuticas nos levaram a considerar enucleação que foi descartada pelos pais. Após recente ressonância magnética nuclear (RMN) negativa, a catarata foi removida. Foi então detectada recorrência tumoral. O olho foi enucleado há 12 meses e ela se recuperou bem da cirurgia. Enquanto a oncologia ocular embarca em tratamentos para preservar em retinoblastoma, é importante considerar os efeitos cumulativos e impacto associado desses tratamentos, e a possibilidade de fracasso.

Descritores: Retinoblastoma/quimioterapia; Retinoblastoma/cirurgia; Melfalan/ administração \& dosagem; Corpo vitreo/patologia; Injeções intravítreas; Neoplasias da retina/cirurgia; Enucleação ocular; Humanos; Feminino; Criança; Relatos de casos

\section{INTRODUCTION}

Retinoblastoma remains the most common pediatric intraocular tumor ${ }^{(1,2)}$. While current therapies have significantly limited patient mortality, the focus has recently shifted towards eye-preserving treatments. These new eye-preserving therapies are particularly relevant to $40 \%$ of the RB cases that are bilateral(3). Periocular chemotherapy, selective ophthalmic artery infusion chemotherapy (SOAIC), and intravitreal (IVit) chemotherapy are relatively recent therapeutic options that have shown potential for eye-preservation ${ }^{(4-6)}$. The ultimate goal of these therapies is to deliver a locally toxic dose of chemotherapeutic agent while avoiding the systemic side effects seen in intravenous chemotherapy ${ }^{(7)}$.

Periocular carboplatin has been used to deliver a high, stable concentration of chemotherapeutic agents by sub-Tenon injection ${ }^{(8)}$. Reports indicated a favorable clinical response with tumor regression, but long-term follow-ups have shown tumor recurrence and disease progression in the eyes treated with periocular carbo- platin ${ }^{(4)}$. Side effects of this treatment include orbital swelling, orbital fat atrophy, acute vision loss, and optic nerve atrophy/pallor $r^{(4,8)}$.

SOAIC was introduced to deliver chemotherapeutic agents directly into the ocular vasculature in eyes that were thought to be otherwise unsalvageable. SOAIC has been shown to be effective, particularly in Group C and D eyes ${ }^{(9)}$. Its side effects include orbital inflammation and diffuse chorioretinal atrophy, among others ${ }^{(9)}$.

The IVit chemotherapy is the most recent modality developed to deliver the chemotherapeutic agent directly into the vitreous ${ }^{(6,10)}$. Studies have shown clearing of the vitreous seeding and avoidance of enucleation in the majority of cases $^{(6)}$. Complications included transient, localized vitreous hemorrhage.

As these localized chemotherapeutic treatments gain acceptan$c e$, it becomes important to recognize not only their potential effects on visual outcome ${ }^{(4,6,9)}$, but also the cumulative effects of sequential, combined treatments, which present their own complications and warrant new discussion of management strategies.

\footnotetext{
Submitted for publication: August 12, 2013

Accepted for publication: February 10, 2014

Study conducted at University of Cincinnati Medical School and Cincinnati Children's Hospital Medical Center.

University of Cincinnati Medical School, University of Cincinnati Medical Center, Cincinnati, $\mathrm{OH}$, USA.

${ }^{2}$ Cincinnati Children's Hospital Medical Center, Cincinnati, OH, USA.
}

Funding: This work was partially supported by an unrestricted grant from Research to Prevent Funding: This work was partially supported by an unrestricted grant from Research to Prevent
Blindness to James J. Augsburger, MD, Chairman, Department of Ophthalmology, University of Cincinnati College of Medicine.

Disclosure of potential conflicts of interest: None of the authors have any potential conflicts of interest to disclose.

Corresponding author: Zélia M. Corrêa. 260 - Stetson Street, Suite 5300 - Cincinnati - OH - 45267 EUA - E-mail: correazm@uc.edu 
Our case report aims to discuss this contemporary dilemma in the multi-modality eye-preserving treatment of retinoblastoma.

\section{CASE REPORT}

A 4 year-old girl with nonfamilial bilateral retinoblastoma was referred to our care, with refractory disease in her remaining eye. She had been treated elsewhere by primary enucleation, intravenous (IV) chemotherapy, laser/cryotherapy, and I-125 brachytherapy OD. Vitreous seeding and chorioretinal scarring with an inferior partial rhegmatogenous retinal detachment OD prompted referral to our center. No discrete tumor was visible, but vitreous seeding was confirmed (Figure 1 A). The patient underwent 6 sessions of singledrug Ophthalmic Artery Infusion Chemotherapy (OAIC) (topotecan) and 2 sessions of OAIC topotecan with subtenon carboplatin. After a sub-optimal response, 2 additional sessions of single-drug OAIC (melphalan) were given. Following the treatment, the vitreous seeding resolved (Figure $1 \mathrm{~B}$ ), but the patient was noted to have diffuse keratopathy, posterior synechiae, cataract, diffuse conjunctival hyperemia, and localized inferior fornix necrosis (Figures 2 A, B). Her keratopathy was managed with the help of a therapeutic contact lens.

Unfortunately, her vitreous seeding relapsed 6 months later (Figure 1C). She then underwent IVit chemotherapy (melphalan $20 \mu \mathrm{g} / 0.1 \mathrm{~mL}$ ) as previously reported ${ }^{(9)}$. The vitreous seeding resolved following the first IVit injection, but she complained of foreign body pain. She received one subsequent injection (Figure $1 \mathrm{D}$ ). Examination throughout the 6 months that followed showed continued vitreous clearing.

Regardless of 3 sequential placements of Prokera ${ }^{\circledR}$ (Biotissue, Mia$\mathrm{mi}, \mathrm{FL}$ ) and 2 tarsorrhaphies, her chronic keratopathy progressed (Figure 2C). Eventually, the keratopathy improved and her inferior fornix healed (Figure $2 \mathrm{D}$ ), but her cataract worsened, precluding a view of the fundus. Magnetic resonance imaging (MRI) showed the vitreous to be clear, prompting a subsequent uneventful cataract surgery. Fundus exam performed after the cataract removal revealed massive tumor recurrence. Therefore, the eye was enucleated. Histopathology showed the optic nerve margin to be tumor free. However she had massive invasion of the choroid inferiorly. She has been tumor free for 12 months after secondary enucleation.

\section{DISCUSSION}

Retinoblastoma presents a unique narrative on the need for effective communication between physicians and families in order to establish realistic therapeutic expectations. This discussion is of paramount importance to children with only one remaining eye. In modern times, physicians and families have looked to new, eye-preserving therapies to avoid enucleation. As these therapeutic options begin to be widely used, one must address the cumulative effects and associated impact of such treatments.

Our patient's clinical course reflects these concerns. On presentation, she had already undergone primary enucleation OS and intense treatment OD that included IV chemotherapy, followed by sequential aggressive local therapy (SALT) and I-125 plaque brachytherapy. Although the toxicity of these combined treatments has not been documented, it has been reported that IV chemotherapy increases the risk for radiation retinopathy following I-125 plaque therapy ${ }^{(11)}$. Although salvage of the eyes with diffuse vitreous or extensive subretinal seeding can be achieved with such treatments in a minority of cases ${ }^{(11)}$, these treatments may have contributed to retinal scarring and detachment, which, in addition to the vitreous seeding, threatened the vision in our patient's only eye.

Our decision to use OAIC with additional periocular carboplatin as salvage therapy was based on the premise that this combination effectively delivers high-dose chemotherapy to the eye while sparing the side effects of systemic treatment. OAIC is currently used as a single or multi-drug treatment ${ }^{(5)}$. At the time we first saw this patient, our institution had initiated a protocol with topotecan (dose based on child's age) as a single agent in an attempt to minimize the side effects of Melphalan, a toxic alkylating agent. After several cycles of treatment and limited response, she was switched to Melphalan. Currently, Melphalan is being used as a single agent in some treatmentnaïve patients, using doses in the range of 3 to $5 \mathrm{mg}$, depending on
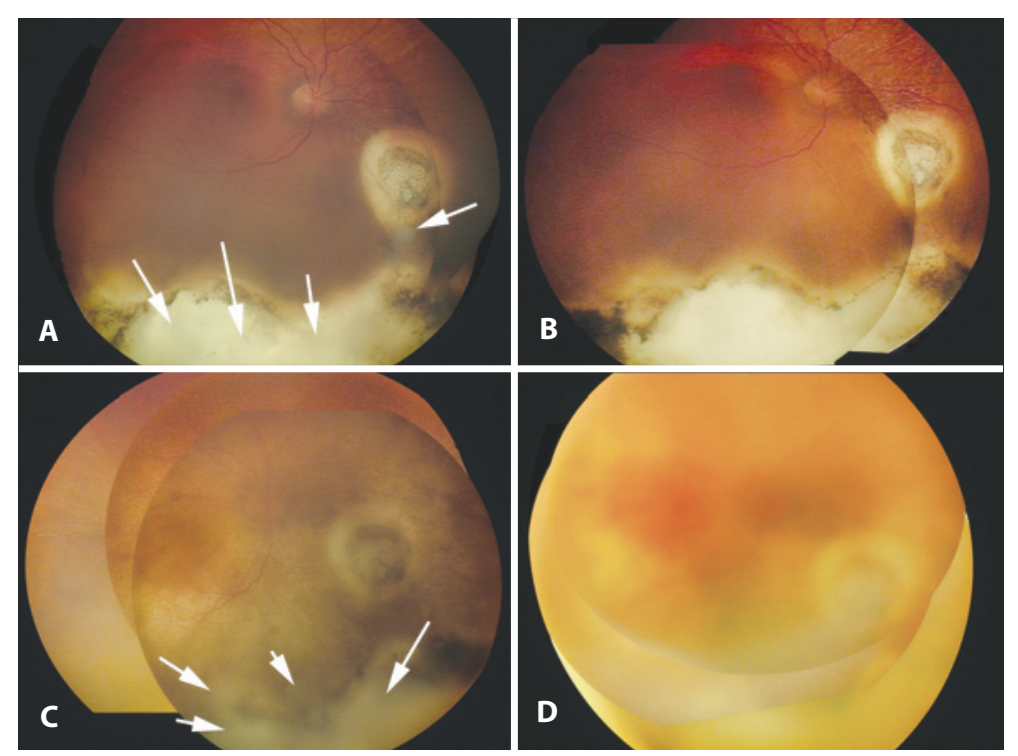

Figure 1. RetCam ${ }^{\oplus}$ photographs of the patient's right eye at various time points. A) First exam at presentation. Note the extensive chorioretinal scarring inferiorly and poorly differentiated matte of preretinal acellular vitreous seeds. B) Following single-drug ophthalmic artery infusion chemotherapy (OAIC) using topotecan (8 sessions), and single-drug OAIC using melphalan (2 sessions), periocular injection carboplatin ( 2 sessions). Note the absence of preretinal vitreous seeds on exam. C) Recurrence of vitreous seeds OD 6 months after the completion of the previous treatment. D) Following the completion of intravitreal melphalan. Note the resolution of vitreous seeding. 

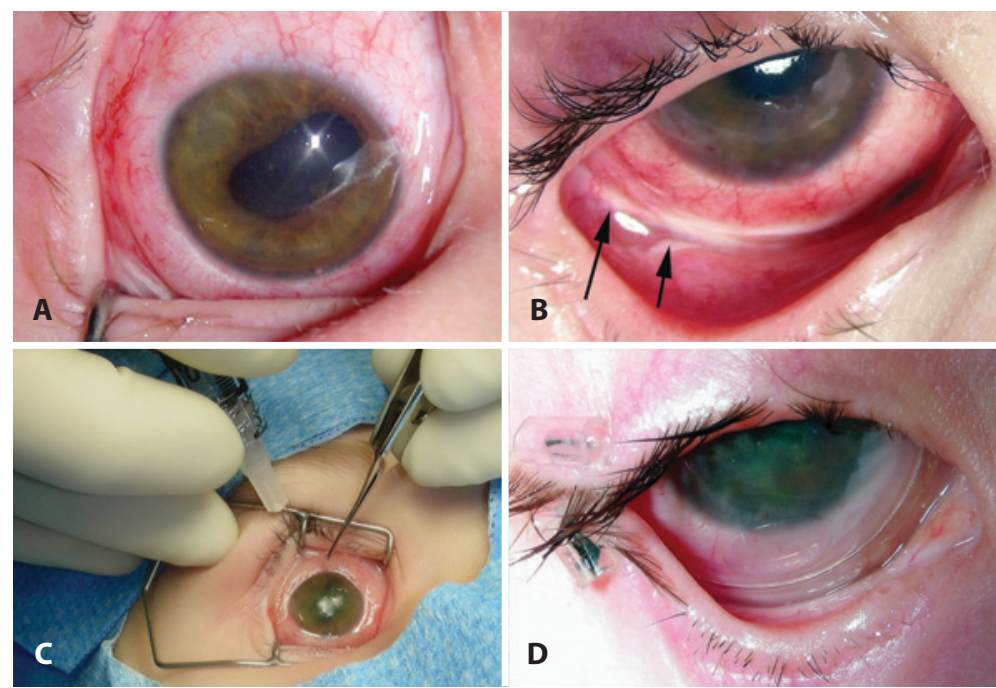

Figure 2. The complications of extensive and intensive treatment for intraocular retinoblastoma. A) Anterior segment photograph OD. Note the secondary cataract and the irregular pupil due to posterior synechiae. B) External photograph OD. Note the inferior fornix necrosis and the limited orbital fat atrophy. C) External photograph OD showing a Prokera ${ }^{\oplus}$ implant over the cornea. This device is a cryopreserved double amniotic membrane graft set in a thermoplastic ring, allowing implantation similar to a contact lens. D) Follow-up external photograph OD (3 months later). Note the neovascularization of the inferior cornea and the partial tarsorrhaphy placed for the management of the patient's chronic keratopathy.

the child's age and weight. In cases that prove to be refractory to OAIC treatment or in case of a late tumor relapse, some centers use a 3-drug regimen (melphalan 3-5 mg, Topotecan 0.3 to $0.5 \mathrm{mg}$, carboplatin 20-30 mg $)^{(5)}$. Although our patient's vitreous seeding resolved, its recurrence demanded a new discussion with the family regarding further management options. The family's decision to preserve her eye prompted the use of Melphalan intravitreously.

Although the eye was tumor free, the patient faced complications resulting from her many treatments. She developed a chronic keratopathy, which caused severe, persistent pain and loss of vision. Amniotic membrane graft and limbal stem cell transplant were discussed. Her prior periocular chemotherapy had resulted in necrosis of the inferior fornix, prohibiting the suturing of an amniotic membrane graft. Although the complications of periocular carboplatin administration have been reported, these complications tend to be variable and dose-dependent ${ }^{(12)}$. The use of periocular carboplatin was thoroughly discussed and was concluded to be a good option based on the reported synergy with topotecan ${ }^{(13)}$. Limbal stem cell transplant from the patient's mother was deemed unsuitable. Therefore, the focus shifted toward the placement of Prokera ${ }^{\circledR}$, a double amniotic membrane graft with implantation similar to a contact lens. Sequential placements of Proker ${ }^{\circledR}{ }^{\circledR}$ healed the previously necrotic inferior fornix. Unfortunately, the patient's cataract and small pupil, which severely limited her vision, precluded fundus examination and our ability to monitor any tumor recurrence. Knowing the risks of cataract surgery, the patient's parents chose to proceed with an MRI. After having put much effort to eradicate her RB, the final decision to enucleate her remaining eye was very difficult. However, the tumor recurrence left us with no other choice.

Modern management of retinoblastoma requires that physicians be aware of the benefits and limitations of new eye-preserving therapies. These novel treatment modalities require a multi-disciplinary, open approach with families. As seen with our patient's chronic keratopathy and secondary cataract, the cumulative side effects of multiple therapies are still unknown and have limited our management options. This is of particular concern when complications preclude active assessment of tumor recurrence. Although tumor suppression is the main treatment goal, it is imperative that physicians consider the long-term consequences of these progressive therapies and their impact on the lives of these children. Finally, it is important to realize that, at times, even extensive efforts may fail to save the child's eye. In doing so, collectively, we will be more mindful of the treatment-associated morbidity and will anticipate the potential side effects and complications to possibly achieve better outcomes and improve patients' quality of life.

\section{REFERENCES}

1. Abramson DH. Retinoblastoma incidence in the United States. Arch Ophthalmol. 1990; 108(1):1514. Comment on: Arch Ophthalmol. 1990;108(1):128-32.

2. Tamboli A, Podgor MJ, Horm JW. The incidence of retinoblastoma in the United States: 1974 through 1985. Arch Ophthalmol. 1990;108(1):128-32. Comment in: Arch Ophthalmol. 1990;108(11):1514.

3. Shields JA, Shields CL. Ocular tumors. A text and atlas. Philadelphia, PA: Saunders; 1992

4. Marr BP, Dunkel IJ, Linker A, Abramson DH. Periocular carboplatin for retinoblastoma: long-term report (12 years) on efficacy and toxicity. Br J Ophthalmol. 2012;96(6):881-3.

5. Abramson DH, Marr BP, Dunkel IJ, Brodie S, Zabor EC, Driscoll SJ, et al. Intra-arteria chemotherapy for retinoblastoma in eyes with vitreous and/or subretinal seeding: 2-year results. Br J Ophthalmol. 2012;96(4):499-502.

6. Munier FL, Gaillard MC, Balmer A, Soliman S, Podilsky G, Moulin AP, et al. Intravitrea chemotherapy for vitreous disease in retinoblastoma revisited: from prohibition to conditional indications. Br J Ophthalmol. 2012;96(8):1078-83.

7. Rizzuti AE, Dunkel IJ, Abramson DH. The adverse events of chemotherapy for retinoblastoma: what are they? Do we know? Arch Ophthalmol. 2008:126(2):862-5

8. Abramson DH, Frank CM, Dunkel IJ. A Phase I/II study of subconjunctival carboplatin for intraocular retinoblastoma. Ophthalmology. 1999;106(10):1947-50.

9. Suzuki S, Yamane T, Mohri M, Kaneko A. Selective ophthalmic arterial injection therapy for intraocular retinoblastoma: the long-term prognosis. Ophthalmology. 2011; 118(10):2081-7.

10. Kaneko A, Suzuki S. Eye-preservation treatment of retinoblastoma with vitreous seeding. Jpn J Clin Oncol. 2003;33(12):601-7.

11. Murphree AL, Villablanca JG, Deegan WF 3rd, Sato JK, Malogolowkin M, Fisher A, et al. Chemotherapy plus local treatment in the management of intraocular retinoblastoma. Arch Ophthalmol 1996;114(11):1348-56.

12. Schmack I, Hubbard GB, Kang SJ, Aaberg TM, Grossniklaus HE. Ischemic necrosis and atrophy of the optic nerve after periocular carboplatin injection for intraocular retinoblastoma. Am J Ophthalmol. 2006;142(2):310-5.

13. Nemeth, KM, Federico S, Carcaboso, AM, Shen Y, Schaiquevich $P$, Zhang J, et al. Subconjunctival carboplatin and systemic topotecan treatment in preclinical models of retinoblastoma. Cancer. 2011;117(2):421-34. 